\title{
Effect of Tris Egg Yolk and Tris Soya Lecithin Extenders in Frozen Beetal Buck Semen
}

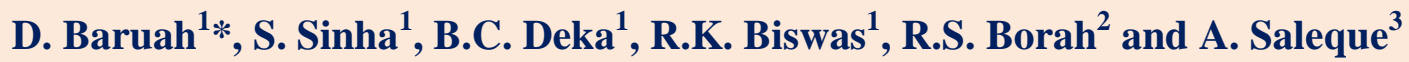 \\ ${ }^{1}$ Department of Animal Reproduction, Gynaecology \& Obstetrics, College of Veterinary \\ Science, AAU, Khanapara, Guwahati-22, India \\ ${ }^{2}$ Department of L.P.M. (Biostat) College of Veterinary Science, AAU, Khanapara, \\ Guwahati-22, India \\ ${ }^{3}$ Goat Research Station, A. A. U., Burnihat, India \\ *Corresponding author
}

\begin{tabular}{|l|}
\hline Ke y w o r d s \\
Tris soya lecithin, \\
Soya lecithin, \\
Cryopreservation, \\
Buck, Host-reacted, \\
French straw
\end{tabular}

\section{Introduction}

Tris-based extenders with egg yolk have been widely used for the freezing of buck spermatozoa (Salamon and Ritar, 1982; Deka and Rao, 1984). It provides successful protection to sperm against cold shock and lipid-phase transition effect during the freezethaw process (Moussa et al., 2002). The low
The aim of this study was to evaluate the effect of Tris egg yolk and Tris soya lecithin in extenders for goat sperm cryopreservation. A total of 15 pooled ejaculates from five adult Beetal bucks maintained at Goat Research Station, AAU, Burnihat, were used in the study. Immediately after collection each ejaculate was evaluated for volume, mass activity and initial sperm motility and those found suitable were pooled. The pooled ejaculates were split into two equal parts and extended with two extenders i.e., Tris extender containing 20 per cent egg yolk (TEY) and Tris extender supplemented with 1.5 per cent soya lecithin (TSL). The extended semen was filled in $0.25 \mathrm{ml}$ French straws and frozen using liquid nitrogen vapour. The mean post-thaw sperm motility, live sperm and intact acrosome in Tris extender containing 20 per cent egg yolk was significantly higher than that in Tris extender containing 1.5 per cent soya lecithin. The mean post-thaw HOST-reacted spermatozoa was non significant between Tris extenders containing 20 per cent egg yolk and 1.5 per cent soya lecithin. In conclusion, although soya lecithin represent an alternative chemically defined extender with decrease risk of biological contamination, egg yolk based extenders are more efficient for cryopreservation of goat semen. 
Despite the significant benefits of egg yolk on semen cryopreservation, such components of animal origin may represent a potential microbiological risk, compromising the quality of cryopreserved semen. Nevertheless, the use of egg yolk as a cryoprotectant has recently been restricted in some countries for reasons of immunologic and hygienic risks. Moreover there is an increased global concern regarding microbiological safety. The World Organization for Animal Health recommended that animal origin products used in semen processing should be free of any biological risk (Marco-Jimenez et al., 2004).Therefore, recent studies are in progress aiming to develop chemically defined extenders, free of compounds of animal origin. On the other hand, the problem about using extenders containing egg yolk in goat semen has been attributed to an enzyme from bulbourethral gland called egg yolk coagulating enzyme (EYCE) later identified as phospholipase A. The interaction between this enzyme and egg yolk can be harmful to the sperm cells.

An alternative to replace the components of animal origin in semen extenders is the soy lecithin, a natural mixture of phosphatidyl choline and several fatty acids such as stearic, oleic, and palmitic. Such fatty acids, the prevailing phospholipids in most of the mammalian biological membranes, are known to confer structural stability to cells (Oke et al., 2010). Due to such composition, studies aiming to evaluate the efficiency of soy lecithin as a primary source of lipoproteins in semen extenders were performed in bovine (Aires et al., 2003; Bousseau et al., 1998; Munoz et al.,2009), buffalo (Akhter et al., 2010), ovine (Gil et al., 2003) and equine (Papa et al., 2010). However, results obtained using lecithin as substitutes to egg yolk are still a matter of debate and Tris-egg yolkfructose extender is still the most commonly employed extender worldwide. Therefore, the present study aimed to compare the efficacy of soya lecithin based extender with that containing 20 per cent egg yolk.

\section{Materials and Methods}

Five Beetal bucks aged two to four years, maintained at Goat Research Station, Assam Agricultural University, Burnihat were used in the study. The bucks were thoroughly examined for sexual and general health before being selected for the present study. Semen was collected from each buck once or twice a week with the help of a standard artificial vagina using a restrained doe. A total of 25 pool ejaculates were used in the study. Immediately after semen collection the glass graduated centrifuge tube containing semen is kept in a beaker containing warm water $\left(35^{\circ} \mathrm{C}\right)$. The semen was then evaluated for volume, mass activity and initial sperm motility. The ejaculates having volume $0.5 \mathrm{ml}$ or more, mass activity ( 0 to $4+$ scale) $3+$ or more and initial motility 70 per cent or more were used in the study. The pooled semen was split into two equal parts and extended in two extenders i.e., Tris extender containing 20 per cent egg yolk and Tris extender supplemented with 1.5 per cent soya lecithin (P3644 Sigma L-a-Phosphatidylcholine from soybean, Type IV-S, $\mathrm{P} \leq 30 \%$ enzymatic). The beaker containing diluted semen sample tubes was then placed in a vaccine carrier and brought to the frozen semen laboratory at Khanapara within 20 mins. In the laboratory the beaker containing the semen samples were kept at room temperature for gradual cooling. The extended semen was filled in $0.25 \mathrm{ml}$ French mini straws by suction at room temperature and sealed by tapping against $10 \mathrm{~mm}$ layer of polyvinyl alcohol powder. The sealed straws were then placed in a tray containing water at room temperature to ensure proper hardening of the seal. The sealed semen straws were cooled gradually to $5^{\circ} \mathrm{C} @ 1^{\circ} \mathrm{C} / 3$ minutes by placing crushed ice in the tray containing water and then equilibrated in the cold 
handling cabinet $\left(5^{\circ} \mathrm{C}\right)$ for $4 \frac{1}{2}$ hours. Thirty minutes before the end of equilibration period the straws were taken out from water and wiped dry using pre-cooled $\left(5^{\circ} \mathrm{C}\right)$ towel. After drying, the straws were arranged in a freezing rack horizontally and frozen in liquid nitrogen vapour (4 cm above liquid nitrogen) for 15 minutes inside a thermocol box. Immediately after freezing, the frozen semen straws were directly plunged in liquid nitrogen and collected in a goblet containing liquid nitrogen and transferred to liquid nitrogen container for storage. On the following day the frozen semen was thawed in warm water at $37^{\circ} \mathrm{C}$ for 30 seconds and was evaluated for sperm motility, live sperm, intact acrosome and HOST-reacted sperm.

\section{Semen evaluation}

\section{Sperm motility}

For estimation of sperm motility, a drop of thawed semen was placed on pre-warmed glass slide $\left(37^{\circ} \mathrm{C}\right)$ and examined under a coverslip at a magnification of $400 \mathbf{x}$ using a compound microscope. The sperm motility was recorded on visual appraisal from 0-100 based on the percentage of progressively motile sperm.

\section{Live sperm}

The percentage of live spermatozoa in frozenthawed semen was determined using EosinNigrosin staining technique described by Blom (1977). The staining solution was prepared by mixing 1part of 5 per cent Eosin and 4 parts of 10 per cent Nigrosin stain and kept at $5^{\circ} \mathrm{C}$ in a refrigerator. One drop of thawed semen was mixed with 4 drops of pre warmed $\left(37^{\circ} \mathrm{C}\right)$ staining solution and allowed to stand for 5 minutes. A thin smear was then prepared on a clean grease-free glass slide with the help of smooth edge of another slide and 200 spermatozoa were examined in different areas of the smear brought under focus using oil immersion objective at a magnification of $1000 \mathrm{X}$ of a compound microscope for determining the percentage of live spermatozoa. Spermatozoa which were not stained were considered live and stained or partially stained were considered as dead.

\section{Intact acrosome}

The incidence of intact acrosome was studied in stained smears of frozen-thawed semen using Giemsa staining technique (Watson, 1975). A total of two hundred spermatozoa were examined in each smear at a magnification of $1000 \mathrm{X}$ under oil immersion objective of a compound microscope to determine the percentage of intact acrosome.

\section{Giemsa staining procedure}

Frozen-thawed semen smear was prepared on a clean, dry glass slide and then dried in air. Immediately after drying the semen smear was fixed in Hancock's fixative for 15 minutes. The semen smear was then washed in slow running tap water for 20 minutes.

After rinsing briskly in distilled water the smear was stained in freshly prepared

Giemsa working solution for 12 hours or overnight. After staining, the slide was rinsed quickly in distilled water, dried in air and mounted using DPX mountant.

\section{HOST-reacted sperm}

The functional integrity of the sperm membrane was studied as per the method described by Revell and Mrode (1994) using Hypo-Osmotic solution.

Frozen-thawed semen 0.1 was mixed with $1 \mathrm{ml}$ of Hypo-osmotic solution in a small test tube at $37^{\circ} \mathrm{C}$. The suspension was incubated in a water bath at $37^{\circ} \mathrm{C}$ for 60 minutes. In case the spermatozoa were observed at a later date, 
they were fixed with $0.1 \mathrm{ml}$ formaldehyde after incubation. A small drop of well-mixed sperm suspension after incubation was placed on a clean, dry and grease-free glass slide and a cover slip was placed over it. Two hundred spermatozoa were examined at a magnification of $400 \mathrm{X}$ using a phase contrast microscope for sperm swelling (coiled tail). Swollen spermatozoa having coiled tail was considered as HOST-reacted sperm and calculated in percentage.

\section{Statistical analysis}

Data obtained were analyzed in SPSS version 2.0 software and MS Excel 2010.

\section{Results and Discussion}

The mean values of sperm motility, live sperm, intact acrosome and HOST-reacted sperm after freezing of Beetal buck semen in Tris extender containing 20 per cent egg yolk (TEY) and Tris extender containing 1.5 per cent soya lecithin (TSL) were presented in table 1 . In the present study post-thaw sperm motility, live sperm and intact acrosome in Tris extender with 20 per cent egg yolk was significantly $(\mathrm{P}<0.05)$ higher than that in Tris extender containing 1.5 per cent soya lecithin. After freezing the mean HOST-reacted spermatozoa did not differ significant between Tris extenders containing 20 per cent egg yolk and 1.5 per cent soya lecithin.

The present study evaluated the efficacy of conventional Tris based egg yolk and Tris based soya lecithin extender on cryopreserved Beetal buck semen. An alternative to replace the components of animal origin in semen extender is the soy-lecithin, a natural mixture of phosphatidylcholine and several fatty acids such as stearic, oleic and palmitic. Such fatty acids are similar to the prevailing phospholipids in most of the mammalian biological membrane that are known to confer structural stability to cells (Oke et al., 2010). Previous studies suggested that addition of soy-lecithin to semen extender improved postthaw sperm motility, viability, acrosome integrity and sperm membrane structure in human (Reed et al., 2009), boar (Zhang et al., 2009), stallion (Papa et al., 2011), bull (Akhter et al., 2012), ram (Emamverdi et al., 2013), buffalo (Chaudhari et al., 2015) and goat (Vidal et al., 2013; Salmani et al., 2014; Lekshmi Bhai et al., 2015).

Result of the present study showed that the post-thawed sperm motility of Beetal buck was superior in Tris egg yolk extender compared to Tris soya lecithin extender. This result is similar to previous report by Chelucci et al (2015)in Goat, Ustuner et al (2014) in Ram and Crespilho et al (2012) in Bovine. Ealier studies in ram and goat semen cryopreservation reported no differences in motility between egg yolk and lecithin-based extenders (Salmani et al.,2014; Forouzanfar et al.,2010), whereas other authors found that lecithin-based extenders has higher motility rates compared with egg yolk-based extenders (Lekshmi Bhai et al., 2015). The beneficial effect of egg yolk may due to its cryoprotective abilities and nutritive properties (Ustuner et al., 2011). Moreover, the variations might be due to the differences in breed of buck, extender components, processing, freezing and thawing procedures used. Sperm motility is essential for normal fertilization, and it is still currently the most common parameter of "sperm quality" acting as an indirect measure of metabolic activity and sperm viability (Chelucci et al., 2015).

Significantly $(\mathrm{P}<0.05)$ higher live sperm percentage after freezing in Tris extender containing 20 per cent egg yolk than in that containing 1.5 per cent soya lecithin extender recorded in the present study was in agreement with the findings of Salmani et al (2013) in Mahabadi goat semen who found 
after freezing significantly higher sperm viability in Tris extender containing 15 per cent egg yolk than in that supplemented with 10 per cent soy-lecithin. Chelucci et al (2015) also reported that in Sarda buck of Italy Tris extender supplemented with 20 per cent egg yolk led to highest viability after freezing as compared to Tris with 1 per cent soy-lecithin and Ovixcell extender. Similarly, other workers also obtained significantly higher live sperm percentage in Tris extender containing egg yolk than in commercial soybean-based extender for Punganur bull (Veerabramhaiah et al., 2012 with Biociphos Plus) and Surti buffalo semen (Chaudhari et al., 2015 with Bioxcell).

In the present study per cent of intact acrosome after freezing was significantly $(\mathrm{P}<0.05)$ higher in Tris extender containing 20 per cent egg yolk than in that containing 1.5 per cent soya lecithin. However, our study are in agreement with the finding of Yodmingkwan et al (2016) in Boer goat semen who observed after freezing significantly higher percentage of intact acrosome in Tris extender containing $2.5 \%$ egg yolk than in that containing 1.5 per cent soybean lecithin. The result of the study is similar with the study of Khalifa and AbdelHafez (2014) in Ram. Veerabramhaiah et al (2012) in bull semen also found significantly higher percentage of intact acrosome in Tris extender than in commercial Biociphos Plus extender after freezing. Chaudhari et al (2015) also reported significantly $(\mathrm{P}<0.05)$ higher incidence of intact acrosome after freezing in Tris extender than in commercial Bioxcell extender. According to Singh et al (2013) and Rehman et al (2014) optimal soya lecithin concentration in the extender is prerequisite for protection of spermatozoa during temperature variations. Concentration of soybean below or above the optimal may be harmful and this might be the reason for poor performance of the soya lecithin extender in the study.

The percentage of HOST-reacted sperm after freezing in Tris extender containing 20 per cent egg yolk than in that containing 1.5 per cent soya lecithin extender was non significant.

This is in agreement with the findings of earlier workers by Lekshmi Bhai et al., (2015) after freezing in Malabari buck semen extended in Tris egg yolk and Andromed extenders and Salmani et al (2014) in Mahabadi buck extended in Tris egg yolk and soybean lecithin based extender. Similarly, Akhter et al (2010) also did not observe any significant difference in post-thaw percentage of HOST-reacted sperm in Nili-Ravi buffalo semen diluted in commercial Bioxcell extender and Tris-citric-egg yolk extender. These variation probably due to the different protocol of cryopreservation, time of equilibration, goat breed and protocol for preparing soybean lecithin extender.

Although the mechanism by which soybean lecithin protects sperm during freezing remains unknown, there are two hypotheses to explain the phenomenon. Phospholipids, being the major component of sperm membrane, play important physiological functions in reducing the freezing point, thus avoiding the formation of large ice crystals, and in minimizing the replacement of plasmalogens to reduce the possible mechanical damage to the sperm membrane (Graham and Foote., 1987; Giraud et al., 2000; Waterhouse et al., 2006). Therefore, the exogenous phospholipids present in extenders can replace some of the sperm membrane phospholipids to maintain plasma membrane structure and function (Graham and Foote, 1987; Trimeche et al., 1997; Zhang et al., 2009). 
Table.1 Effect of TEY and TSL semen extenders on post-thawed semen parameter (Mean \pm SE)

\begin{tabular}{|l|l|l|}
\hline Parameter & TEY & TSL \\
\hline Sperm motility & $56.07 \pm 1.03^{\mathrm{a}}$ & $51.07 \pm 1.28^{\mathrm{b}}$ \\
\hline Live sperm & $62.20 \pm 1.12^{\mathrm{a}}$ & $53.07 \pm 1.51^{\mathrm{b}}$ \\
\hline Intact acrosome & $61.40 \pm 0.87^{\mathrm{a}}$ & $51.09 \pm 0.87^{\mathrm{b}}$ \\
\hline Host-reacted sperm & $48.47 \pm 0.99^{\mathrm{a}}$ & $47.73 \pm 0.52^{\mathrm{a}}$ \\
\hline
\end{tabular}

Another possibility, also widely accepted by many researchers, is that the egg yolk phospholipids or soy lecithin do not enter the membrane to alter the phospholipids concentration but may form a protective film around the cell to prevent the formation of intracellular ice crystals and to protect the sperm membrane from mechanical damage during freezing (Zhang et al., 2009). The active fraction of egg yolk that gives protection is believed to be a low density lipoprotein (Watson and Martin, 1975). Lecithin in soybean and egg yolk protects sperm membrane phospholipids and increases the tolerance of spermatozoa to freezing process (Moussa et al., 2002). However, there are several differences in the structure of lecithin derived from egg yolk and those derived from plants such as soy-lecithin (Lekshmi Bhai et al., 2015). Moreover, there are conflicting reports concerning the beneficial effect of lecithin (Forouzanfar et al. 2010; Papa et al, 2011). The advantages of lecithin based extender over egg yolk regarding sanitary issues are unquestionable. However, the hypothesis that cryoprotective capacity of soy-lecithin is similar to that provided by egg yolk was not confirmed in the present study and the efficacy of lecithinbased extender in preserving goat semen is yet to be determined unequivocally.

In conclusion, freezing of Beetal goat semen with an extender containing egg yolk found to be comparatively superior in post-thaw sperm parameters compared to soya lecithin-based extender. Further studies should be performed to determine the lecithin concentration and extender preparation technique that would improve frozen semen quality.

\section{Acknowledgement}

The authors would like to acknowledge the support of college of veterinary science, Assam Agricultural University, Khanapara, Guwahati-22 dr. and Goat Research Station, AAU, Burnihat for this research. The author would like to thanks Dr. Manna Baruti and Dr. Raju Deka, Asst. Professor, College of Veterinary Science, Assam Agricultural University, Khanapara, Guwahati-22 for support and motivation during research and during preparation of manuscript.

\section{References}

Aires, V.A., Hinsch, K., Mueller-Schloessor, F., Bogner, K., Mueller-Schloessor, S. and Hinsch, E. 2003. In vitro and in vivo comparison of egg yolk based and soybean lecithin-based extenders for cryopreservation of bovine semen. Theriogenology. 60: 269-279.

Akhter, S., Ansari, M. S. Rakha, B.A., Andrabi, S.M.H., Iqbal, S. and Ullah, N. 2010. Cryopreservation of buffalo (Bubalus bubalis) semen in Bioxcell@ extender. Theriogenology. 74: 951-955.

Akhter, S., Ansari, M.S., Andrabi, S.M., Rakha, B.A., Ullah, N. and Khalid, M. 2012. Soya-lecithin in extender improves the freezability and fertility of buffalo (Bubalus bubalis) bull spermatozoa. Reprod. Domest. Anim. 47(5): 815-819. 
Blom, E. 1977. Sperm morphology with reference to bull infertility. In: Some papers contributed to the First All India Symposium on Animal Reproduction, Punjab Agricultural University, Ludhiana. pp. 61-81.

Bousseau, S., Billard, J.P.; Marquan-Le Guienne, B.; Gurien, B., Camus, A. and Lechat, M. (1998). Comparison of bacteriological qualities of various egg yolk sources and the in vitro and in vivo fertilizing potential of bovine semen frozen in egg yolk free or lecithin based diluents. Theriogenolog., 50: 699-706.

Chaudhari, D.V., Dhami, A.J., Hadiya, K.K. and Patel, J.A. 2015. Relative efficacy of egg yolk and soya milk-based extenders for cryopreservation $\left(-196^{\circ} \mathrm{C}\right)$ of buffalo semen. Vet. World. 8: 239-244.

Chelucci, S., Pasciu, V., Succu, S.; Addis, D., Leoni, G.G.; Manca, M.E., Naitana, S., and Berlinguer, F. 2015. Soybean lecithin-based extender preserves spermatozoa membrane integrity and fertilizing potential during goat semen cryopreservation. Theriogenology, 83: 1064-1074.

Crespilho, A.M.; Sa Filho, M.F.; DellAqua, J.A.; Nichi, M.; Monteiro, G.A.; Avanzi, B.R.; Martins, A. and Papa, F.O. 2012. Comparison of in vitro and in vivo fertilizing potential of bovine semen frozen in egg yolk or new lecithin based extenders. Livestock Science. 149: 1-6.

Deka, B. C. and Rao, A. R. 1984. Effect of separation of seminal plasma on quality of frozen buck semen. Indian J. Anim. Reprod. 5(2): 56-59.

Emamverdi, M., Zhandi, M., Zare Shahneh, A., Sharafi, M. and Akbari Sharif, A. 2013. Optimization of ram semen cryopreservation using a chemically defined soybean-lecithin based extender. Reprod. Domest. Anim. 48(6):
899-904.

Forouzanfar, M., Sharafi, M., Hosseini, S. M., Ostadhosseini, S., Hajian, M., Hosseini, L., Abedi, P., Nili, N., Rahmani, H.R. and Nasr-Esfahani, M. H. 2010. In vitro comparison of egg yolk-based and soybean lecithin-based extenders for cryopreservation of ram semen. Theriogenology.73: 480-487.

Gil, J.; Lundeheim, N., Soderquist, L. and Rodriguez- Martinez, H. 2003. Influence of extender, temperature, and addition of glycerol on post-thaw sperm parameters in ram semen. Theriogenology. 59: 1241-1255.

Giraud, M. N., Motta, C., Boucher, D. and Grizard, G. 2000. Membrane fluidity predicts the outcome of cryopreservation of human spermatozoa. Hum. Reprod. 15: 21602164.

Graham, J. K. and Foote, R. H. (1987). Dilauroylphosphatidylcholine liposome effect on the acrosome reaction and in vitro penetration of zonz-free hamster eggs by bull sperm: A fertility assay for frozen-thawed semen. Gamete Res. 16: 147-58.

Khalifa, E. I. and Abdel-Hafez, M. A. M. 2014. Effect of soybean lecithin-based semen extender on freezability and fertility of Rahmani ram spermatozoa. Egyptian J. Sheep \& Goat Sci. 9 (1): 59 66.

Lekshmi Bhai, K., Joseph, M., Behera, S., Harshan, H.M., Ghosh Aravinda, K. N. and Raghavan, K. C. 2015. Motility and functional membrane integrity of buck spermatozoa with soyabean lecithin based extender. Journal of Cell and Tissue Research. 15 (1): 4711-4714.

Manjunath P. 2012. New insight into the understanding of the mechanism of sperm protection by extender component. Animal Reproduction. 9:809-815. 
Marco-Jimenez, F., Puchades, S., Moce, E., Viudes-De-Cartro, M. P., Vicente, J. S. and Rodriguez, M. 2004. Use of powdered egg yolk vs. fresh egg yolk for the cryopreservation of ovine semen. Reprod. Dom. Anim. 39: 438-441.

Moussa, M., Martinet, V., Trimeche, A., Tainturier, D. and Anton, M. 2002. Low density lipoproteins extracted from hen egg yolk by an easy method: cryoprotective effect on frozen-thawed bull semen. Theriogenology, 57: 16951706.

Munoz, O., Briand, L., Diaz, T., Vasquez, L., Schmidt, E., Desherces, S., Anton, M., Bencharif, D. and Tainturier, D. 2009. Effect of semen dilution to low-sperm number per dose on motility and functionality of cryopreserved bovine spermatozoa using low-density lipoproteins (LDL) extender: comparison to Triladyl and Bioxcell. Theriogenology. 71: 895-900.

Oke, M., Jacob, J.K., and Paliyath, G., 2010. Effect of soy lecithin in enhancing fruit juice/sauce quality. Food Res. Int. 43, 232-240.

Papa, F.O., Felicio G.B., Melo-Õ na, C.M., Alvarenga, M.A. De Vita, B. Trinque. C. Puoli-Filhob, J.N.P. and Dell' Aqu, J.A. 2011. Replacing egg yolk with soybean lecithin in the cryopreservation of stallion semen. Anim. Reprod. Sc. 129: 73-77.

Papa, F.O., Felıcio, G.B., Melo, C.M., Vita, B., Avanzi, B.R. and Aqua, J.A. 2010. Effect of substituting soybean lecithin for egg yolk in an extender used for the cryopreservation of stallion semen. Anim. Reprod. Sci. 121: 71-72.

Reed, M.L., Ezeh, P.C., Hamic, A., Thompson, D.J. and Caperton, C.L. 2009. Soy-lecithin replaces egg yolk for cryopreservation of human sperm without adversely affecting post thaw motility, morphology, sperm DNA integrity, or sperm binding to hyaluronate. Fertil. Steril. 92: 17871790.

Rehman, F. U., Qureshi, M. S. and Khan, R. U. 2014. Effect of soybean based extenders on sperm parameters of Holstein-Friesian bull during liquid storage at $4^{\circ} \mathrm{C}$. Pak. J. Zool.46: 185-189.

Revell, S.G., and Mrode, R.A. 1994.An osmotic resistance test for bovine semen. Animal Reproduction Science 36(1-2):77-86

Salamon, S., and Ritar, A. J.1982. Deep freezing of Angora goat semen: effects of diluent composition and method and rate of dilution on survival of spermatozoa. Aust. J. Bio.l Sci. 35:295-303

Salmani, H., Nabi, M. M., Vaseghi-Dodaran, H., Rahman, M.B., MohammadiSangcheshmeh, A., Shakeri, M., Towhidi, A., Shahneh, A. Z. and Zhandi, M. 2013. Effect of glutathione in soybean lecithin-based semen extender on goat semen quality after freeze-thawing. Small Rumin. Res. 112: 123-127.

Salmani, H., Towhidi, A., Zhandi, M., Bahreini, M. and Sharafi, M. 2014. In vitro assessment of soybean lecithin and egg yolk based diluents for cryopreservation of goat semen. Cryobiology. 68: 276-280.

Singh, A. K., Singh, V. K., Narwade, B. M., Mohanty, T. K. and Atreja, S. K. 2013. Comparative quality assessment of buffalo (Bubalas bubalis) semen chilled $\left(5^{\circ} \mathrm{C}\right)$ in egg yolk and milk based extenders. Reprod.Domes.Anim. 47 (4): 596-600.

Trimeche, A., Anton, M., Renard, P., Gandemer, G. and Tainturier, D. 1997. Quail egg yolk: a novel cryoprotectant for the freeze preservation of Poitou jackass sperm. Cryobiology 34: 385393. 
Ustuner, B., Alcay, S., Nur, Z., Sagirkaya, H. and Soylu, M. K. 2014. Effect of egg yolk and soybean lecithin on tris-based extender in post-thaw ram semen quality and in vitro fertility. Kafkas Univ. Vet. Fak. Derg. 20(3): 393-398

Veerabramhaiah, K.; Seshagiri Rao, A.; Rao, V. H.; Venugopal Naidu, K. and Viroji Rao S. T. 2011. Efficacy of the tris and biociphos plus extenders on the freezability of punganur bull semen. Indian J. Anim. Reprod. 32 (2): 1-4.

Vidal, A. H., Batista, A. M., Bento da Silva, E. C., Gomes, W. A., Pelinca, M. A., Silva, S. V. and Guerra, M. M. P. 2013. Soybean lecithin-based extender as an alternative for goat sperm cryopreservation. Small Rumin. Res. 109: 47-51.

Waterhouse, K. E.; Hofmo, P. O.; Tverdal, A. and Miller Jr., R. R. 2006. Within and between breed differences in freezing tolerance and plasma membrane fatty acid composition of boar sperm. Reproduction. 131: 887-894.

Watson, P. F. and Martin, I. C. A. 1975. Effects of egg yolk glycerol and the freezing rate on the viability and acrosomal structures of frozen spermatozoa. Aust. J. Bio. Sci. 28: 153159.

Yodmingkwan, P., Guntaprom, S., Jaksamrit, J. and Lertchunhakiat, K. 2016. Effects of extenders on fresh and freezing semen of Boer goat. Agriculture and Agricultural Science Procedia. 11: 125130.

Zhang, S. S., Hu, J. H., LI, Q. W., Jiang, Z. L. and Zhang, X. Y. 2009. The cryoprotective effects of soybean lecithin on boar spermatozoa quality. Afr. J. Biotechnol. 8: 6476-6480.

\section{How to cite this article:}

Baruah, D., S. Sinha, B.C. Deka, R.K. Biswas, R.S. Borah and Saleque, A. 2019. Effect of Tris Egg Yolk and Tris Soya Lecithin Extenders in Frozen Beetal Buck Semen. Int.J.Curr.Microbiol.App.Sci. 8(01): 2740-2748. doi: https://doi.org/10.20546/ijcmas.2019.801.290 